\title{
Remarks on the new earthworm taxa described by Aladesida and Owa in 2015 from Nigeria (Clitellata: Megadrili)
}

\author{
Cs. CSUZdi ${ }^{1}$, T. SzEDERJESI ${ }^{2}$, E. SHERLOCK ${ }^{3}$ \\ ${ }^{1}$ Csaba Csuzdi, Department of Zoology, Eszterházy Károly University, Eger, Hungary. \\ E-mail: csuzdi.csaba@uni-eszterhazy.hu \\ ${ }^{2}$ Tímea Szederjesi, Department of Zoology, Hungarian Natural History Museum, Budapest, Hungary. \\ ${ }^{3}$ Emma Sherlock, The Natural History Museum, London, UK.
}

\begin{abstract}
The earthworm fauna of tropical Africa is clearly understudied. This is mainly due to the lack of local earthworm researchers. Nigeria is an exception in this regard with an excellent earthworm researcher A.O. Segun and his successor S.O. Owa describing some 30 earthworm species belonging to the family Eudrilidae. Recently, Aladesida \& Ova (2015) published descriptions of four new earthworm genera and species; Adodrilus stephana (Megascolecidae), Ekitidrilus alabataensis, Paranematogenia eyinwaensis (Ocnerodrilidae), and Imekodrilus hexagastricus (Moniligastridae). Examining the type material of the new taxa deposited in the Natural History Museum, London revealed that Adodrilus stephana Aladesida \& Ova, 2015 is a synonym of Gordiodrilus robustus Beddard, 1892, Ekitidrilus alabataensis Aladesida \& Ova, 2015 represents a nomen nudum. Due to the juvenile state of the types, the names Imekodrilus hexagastricus Aladesida \& Ova, 2015 represent a nomen dubium in the family Ocnerodrilidae and Paranematogenia eyinwaensis a nomen dubium in the family Eudrilidae. To prevent further nomenclatural problems, lectotypes for Adodrilus stephana and Paranematogenia eyinwaensis were designated.
\end{abstract}

Keywords. Africa, Annelida, Oligochaeta, lectotype, synonymy.

\section{INTRODUCTION}

$\mathrm{T}$ he earthworm fauna of tropical Africa is very poorly investigated compared to other tropical regions like Australia, South America or South-East Asia. This is clearly reflected by the ca. 600 earthworm species recorded from Africa, a low number comparing to the $c a .1000$ species reported from South America (Fragoso \& Brown 2007 ) or the 505 species reported from the much smaller India (Narayanan et al. 2017).

Thanks to the works of A.O. Segun (between 1976-1990) and S.O. Owa (1990-1998) among the tropical African countries Nigeria seems to be the best explored with its some 100 earthworm species. The earthworm fauna of this vast West African country is highly specialised; 10 of the registered 25 genera are endemic to this region. Therefore it is not surprising, that recently two
Nigerian scientists reported four new earthworm genera and species from the country: Adodrilus stephana (Megascolecidae), Ekitidrilus alabataensis, Paranematogenia eyinwaensis (Ocnerodrilidae), and Imekodrilus hexagastricus (Moniligastridae) (Aladesida \& Owa 2015). The new earthworm material was collected in Southwest Nigeria (Ekiti and Ogun States). According to the original descriptions, the holotypes of the new taxa were deposited in the Natural History $\mathrm{Mu}$ seum, London.

In 2013 the first and last author had the possibility to work together on a large unidentified earthworm material collected in West Africa and also to check the type material sent by S. Owa to the Museum in 2012. As at that time neither of the label names were published, we made several notes on the earthworms in each vial and treated them as unpublished manuscript names. 
In the meantime, descriptions of four new genera by Aladesida \& Owa (2015) were published. As all the proposed new names were recorded as problematic or synonyms in our original notes here, we re-examined the type material and concluded that Adodrilus stephana Aladesida and Owa, 2015 is a synonym of the African peregrine Gordiodrilus robustus Beddard, 1892, Ekitidrilus alabataensis Aladesida and Owa, 2015 belongs also to Gordiodrilus rubustus but the name is a nomen nudum because, due to a typesetting error its description lacks explicit indication of describing a new species (ICZN Art 16.1). Imekodrilus hexagastricus Aladesida and Owa, 2015 is an ocnerodrilid species reminiscent of Nematogenia lacuum (Beddard, 1893) however, the holotype is completely juvenile. The fourth new taxon Paranematogenia eyinwaensis Aladesida and Owa, 2015 belongs to the eudrilid subfamily Pareudrilinae Beddard, 1894 close to the genus Pareudrilus Beddard, 1894 however; due to the juvenile state of the two syntypes its exact position cannot be determined.

\section{MATERIAL AND METHODS}

The type material deposited in the Natural History Museum, London was examined using a Nikon SMZ600 stereo microscope. According to the original description the holotypes of the new taxa from Nigeria was deposited in the Museum. Whenever we have found several specimens of a species present, lectotypes were designated to avoid further nomenclatural problems.

\section{TAXONOMY}

\section{Family Ocnerodrilidae Michaelsen, 1900}

\section{Gordiodrilus robustus Beddard, 1892}

Adodrilus stephana Aladesida \& Owa, 2015: 102-103. syn. nov.

Material examined. Adodrilus stephana Aladesida \& Owa, 2015 genus et sp. novo Syntypes,
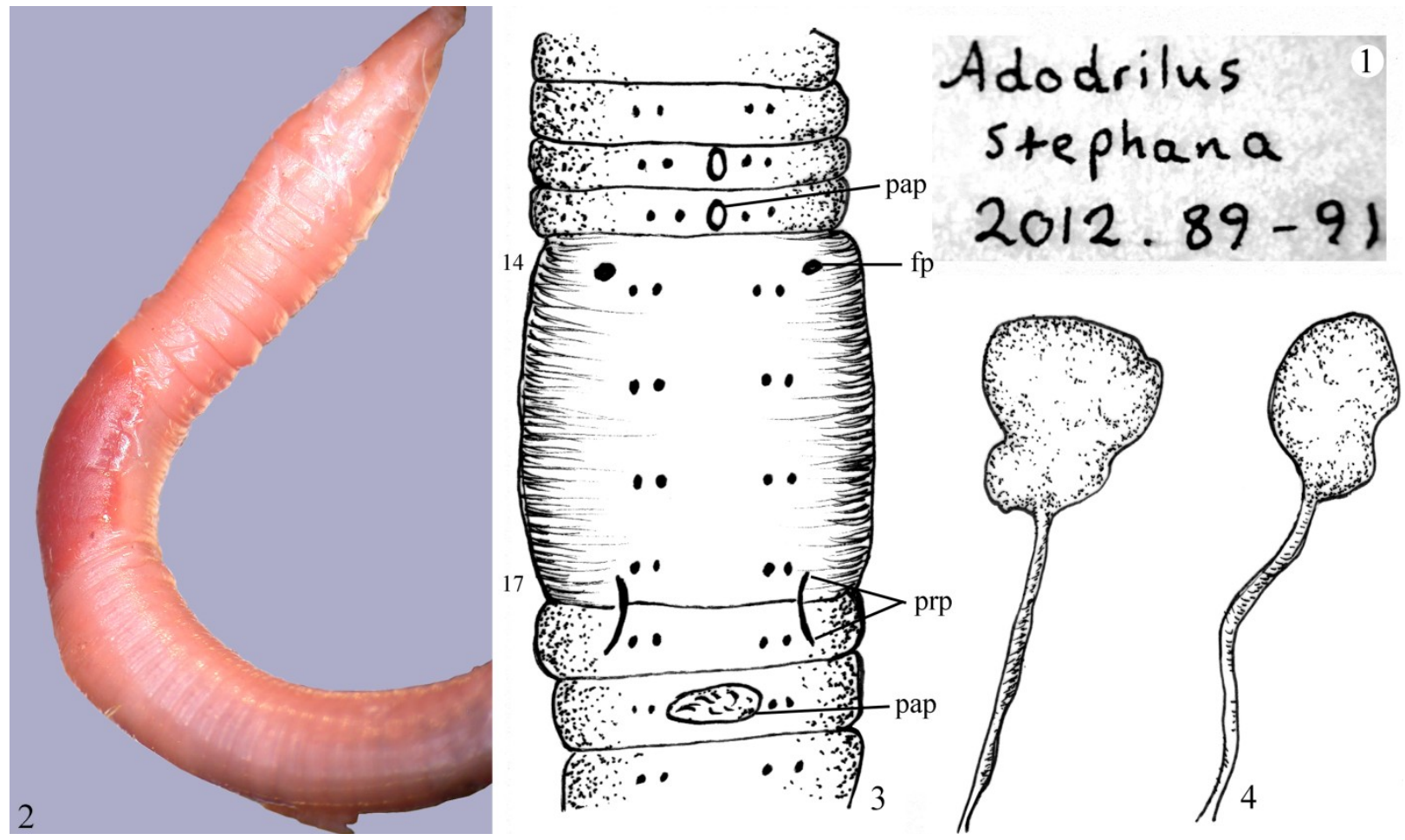

Figures 1-4. Adodrilus stephana Aladesida \& Owa, 2015. 1 = vial label, 2 = habitus fro lateral view, $3=$ clitellar region from ventral view, 4 = spermathecae. $f p=$ female pore, pap $=$ papillae, prp $=$ prostate pores. 
NHM2012.89-91 three clitellate specimens. Nigeria, Ekiti state, Ado-Ekiti. 8/7/2008. Leg. Adeyinka Aladesida.

https://data.nhm.ac.uk/object/67df079f-5dce496d -951c-d7258cd8d0de/1583798400000

Description. Dimensions of the specimens $36 \times 2 \mathrm{~mm}$, segment no. 97; 41x2 mm, segment no. 96; 50x2 mm, segment no. 107. Colour preserved brownish, alive unknown. Head prolobous. First dorsal pore in $11 / 12$. Setae closely paired, setal ratio of the longest specimen $a a: a b: b c: c d: d d=$ $5: 1: 8.5: 1: 22$. Nephridial pores not seen.

Clitellum well developed, saddle-shaped on segments 14-17. Prostatic pores on 17-18 in setal line $b$ connected by straight seminal groves. Male pores not seen. Female pores small dots on 14, praesetal and lateal to $b, c a$. half way between $b$ and $c$ on the lateral edge of the clitellum. Spermathecal pores paired in $6 / 7-7 / 8$ in setal line $b$. Glandular papillae small, midventral on 12,13 and a large prominent glandular pad between $a a$ on 19.

Internal characters. Muscular gizzard vestigial in 7 and strong in 8. Septa 5/6-7/8 thickened. Calciferous glands in 9, single, with bifid ventral projection. Excretory system holoic, avesiculate. Last pair of hearts in 11 . Testes in 10, 11 covered some free sperms, vesicles one pair in 12. Ovaria large in 13. Spermathecae two pairs with a very long and thin, in some part spiral duct and large, more or less oval ampoule. Prostates small simple tubes confined to their own segments. Penial setae lacking.

Remarks. According to the original description "The holotype has been reposited at the British Museum of Natural History, while the syntype is at the Museum of Natural History, Olabisi Onabanjo University, Ago-Iwoye, Nigeria". In NHM London there are 3 specimens with registration number NHM2012.89-91 which should be regarded as syntypes. As the species was described on eight specimens, a further five exemplars were deposited in the Museum of Natural History, Olabisi Onabanjo University, Ago-Iwoye, Nigeria. To avoid further problems here we designate the largest specimen with 107 segment number as lectotype with registration number NHM2012.89.

The authors relegated these specimens to the family Megascolecidae, because they thought that there is only one pair of „bag-shaped" prostates in 17/18. In reality there are two pairs of highly coiled tubular prostates in 17 and 18. Also, the authors did not recognize the first pair of spermathecae in segment 7 which is usually smaller than the next ones in segment 8 and are folded under the oesophagus and if empty, hard to recognize.

The fused calciferous glands, the characteristic spermathecae and the papillae on segments 12,13 and 19 clearly prove that these specimens belong to the local peregrine Gordiodrilus robustus Beddard, 1892 of the family Ocnerodrilidae.

Ekitidrilus alabataensis Aladesida \& Owa, 2015: 105106. nomen nudum

Material examined. Ekitidrilus alabataensis Aladesida \& Owa, 2015 Syntypes, NHM2012.7475 three clitellate specimens. Nigeria, Ekiti state and Ogun state; Ado-Ekiti. 8-12/7-9 2008-2009. Leg. Adeyinka Aladesida.

https://data.nhm.ac.uk/object/579f103c-04e04880-a02b-0dbded201e65/1583366400000

Description. Length of the largest specimen 36 $\mathrm{mm}$, diameter after clitellum $1.5 \mathrm{~mm}$. Segment number 93, tail missing. Length of the smaller specimen $35 \mathrm{~mm}$, diameter $1.5 \mathrm{~mm}$, segment no. 97. The smallest but clitellate specimen $20 \mathrm{~mm}$ in length and $1 \mathrm{~mm}$ in diameter, segment no. 89 . Colour preserved brownish, alive unknown. Head prolobous. First dorsal pore in 11/12. Setae closely paired, setal ratio $a a: a b: b c: c d: d d=$ 4.4:1:6.7:1:22.2. Nephridial pores not seen.

Clitellum saddle-shaped on segments 14-17. Prostatic pores on 17-18 in setal line $b$ connected by straight seminal grooves. Male pores not seen. Female pores small dots on 14, praesetal and lateal to $b, c a$. half way between $b$ and $c$. Spermathecal pores paired in $6 / 7-7 / 8$ in setal line $b$. 
Glandular papillae small, midventral on 12, 13 and a larger on 19.

Internal characters. Muscular gizzard small in 7 and strong in 8 . Septa 5/6-7/8 slightly thickened, 8/9-11/12 moderately strengthened. Calciferous glands in 9, single, with bifid ventral projection. Excretory system holoic, avesiculate. Testes, funnels, vesicles and ovaria missing. Spermathecae two pairs with a very long and thin, in some part spiral duct and small irregularly sackshaped ampoule. Prostates small simple tubes confined to their own segments. Penial setae lacking.

Remarks. The worms, according to their rudimental gizzard in 7 and a large one in 8, the unpaired calciferous gland and characteristic shape of spermathecae clearly belong to the regional peregrine Gordiodrilus robustus. All the two specimens possess slightly degenerated prostates and lack any sign of sperm in the spermathecae, however the clitellum were more or less developed.

Due to a printing error, the name Ekitidrilus alabataensis appears only in the abstract and on $\mathrm{p}$. 106 in the legends of figure 3a. Seemingly the line stating the taxon as new is missing on p. 104 because, after the etymology of an other new taxon Paranematogenia eyinwaensis again comes the heading: "Type locality" which is Ado-Ekiti and Alabata. According to the Code of Zoological Nomenclature "All names: intention of authors to establish new nominal taxa to be explicit. Every new name published after 1999, including new replacement names (nomina nova), must be explicitly indicated as intentionally new" and according to Recommendation 16A: Means of explicitly indicating names as intentionally new. To avoid uncertainty about their intentions, authors proposing new names (nomina nova), including new replacement names, are advised to make their intentions explicit by using in headings, or at first use of new names in proposals, appropriate abbreviations of Latin terms such as ..."sp. nov.", "ssp. nov.", or some strictly equivalent expression such as ..."new species", "new subspecies, ..."n. sp.", "n. ssp." (ICZN Art 16.1). As such kind of indication is missing here and also one can only guess which name the description belong to the name in the abstract and in the figure caption "Ekitidrilus alabataensis" should be regarded as nomen nudum.

Under the heading Type material, the authors write that the "The holotype has been reposited at the British Museum of Natural History, while the syntype is at the Museum of Natural History, Olabisi Onabanjo University, Ago-Iwoye, Nigeria" However, in the Natural History Museum, London the vial registered under No. 2012.74-75 contains 3 specimens with locality Ado-Ekiti. As in the paper the authors state that they had two clitellate specimens from Ado-Ekiti and three from Alabata, the third very small but clitellate specimen in the vial either was overlooked by the authors or accidentally one specimen from Alabata was also put into the vial sent to NHM, London.

\section{Ocnerodrilidae sp. juv.}

Imekodrilus hexagastricus Aladesida \& Owa, 2015: 101-102. nomen dubium

Material examined. Imekodrilus hexagastricus Aladesida \& Owa, 2015 Holotype, NHM2012.72 one juvenile specimen. Nigeria, Imeko. 10/9/ 2009. Leg. Adeyinka Aladesida.

https://data.nhm.ac.uk/object/5c7279f6-2202$\underline{\text { 4041-a335-f6ad56317187/1583798400000 }}$

Description. Length $82 \mathrm{~mm}$, diameter $2 \mathrm{~mm}$, segment no. 194. Colour pale pigmentation lacking. Head epilobous. First dorsal pore in 8/9. Setae closely paired, setal ratio of the longest specimen $a a: a b: b c: c d: d d=5: 1: 8.5: 1: 22$. Nephridial pores not seen. The specimen completely juvenile, no clitellum and genital pores seen.

Internal characters. Muscular gizzard small in 7 and 8. No septa thickened, but the inner organs lacking except a small piece of the oesophagus bearing a paired, forward projecting calciferous glands in 9? The excretory system holoic avesiculate. The intestine lacks typhlosolis. 
Remarks. According to the original description, three aclitellate specimens were collected in Imeko, Ogun State, Nigeria. The holotype was deposited in NHM, London and the two paratypes ("syntype" in the original description) in the Natural History Museum, Olabisi Onabanjo University, Ago-Iwoye, Nigeria.

The holotype specimen is completely juvenile. According to the description, the last pair of hearths is in 11 which, in combination with the paired calciferous glands in 9? and two small gizzards in 7(?) and 8(?) place this specimen in the family Ocnerodrilidae and not Moniligastridae as in the original description. In appearance, the specimens has some similarity to a larger Nematogenia lacuum (Beddard, 1893) specimen but without developed genital characters it cannot be placed into any ocnerodrilid genus reliably.

\section{Family Eudrilidae Claus, 1880}

\section{Pareudrilinae sp. juv.}

\section{Paranematogenia eyinwaensis Aladesida \& Owa, 2015: 104. nomen dubium}

Material examined. Paranematogenia eyinwaensis Aladesida \& Owa, 2015 Syntype, NHM 2012.78-80 three juvenile specimens. Nigeria, Ogun state, Eyinwa. 12/7/2009. Leg. Adeyinka Aladesida.

https://data.nhm.ac.uk/object/ca9d711e-52bf42c5-9a65-39473b662253/1589414400000

Description. Dimensions of the specimens: $105 \times 2 \mathrm{~mm}$, segment no. 221; $55 \times 2 \mathrm{~mm}$, segment no. 126 , tail missing; $55 \times 1.5 \mathrm{~mm}$, segment no. 168. Colour pale. Head epilobous, dorsal pores lacking. Setae $a b$ and $c d$ closely paired, setal ratio $a a: a b: b c: c d: d d=8.8: 1.3: 4.1: 1: 21$, after the prostatic pores the setal distance $a a$ gradually became larger and $a b$ smaller resulted in a very strange setal position with all the four setal line running laterally close to each other $a a: a b: b c: c d: d d=$ 16:1.1:2:1:250. Nephridial pores aligned in setal line $d$. Clitellum not visible, the specimens completely juvenile, only the prostatic pores can be seen as paired, small, keeled Y-shaped slits be- tween $a-a$ in 17. Female pores and spermathecal pores not seen.

Internal characters. Muscular gizzard large in 5. Septa 6/7-8/9 slightly thickened. Calciferous glands lacking, but there is a calciferous gland like vascularization at the end of the oesophagus in 17-18. Last hearts possibly in 12 , small moniliform. Testes and sperm funnels in 11. Vesicles one pair, long coiled tube running dorsally between 12-14. Ovo-spermathecal apparatus just poorly developed, an ovisac and the oviduct seen opening in the setal line $d$ in 14. Prostates small euprostates in developing stage in 17 and the clearly seen male duct join the prostates at the neck. Developing penial setae present in 17 and also the setae in 14-16 developed as genital setae. Nephridial system holoic, vesiculate. Nephridial bladders simple sausage-shaped. Intestine begins abruptly in 20, typhlosolis present as shallow dorsal ridge.

Remarks. Under the heading Type material, the authors write that the „The holotype has been reposited at the British Museum of Natural History, while the syntype is at the Museum of Natural History, Olabisi Onabanjo University, AgoIwoye, Nigeria" However, in the Natural History Museum, London the vial registered under No. NHM2012.78-80 contains 3 specimens with locality Nigeria, Ogun state, Eyinwa. All the three specimens are juvenile but the smallest one lacks any sign of genital pores and also its setal arrangement is different from that of the two larger specimen. As in the original description there are three adult and one juvenile specimen here we designate the most grown broken specimen as lectotype with registration number NHM2012.78.

Unfortunately in the original description there are no dimension data and the specimen at hand differ completely from the original description; only the presence of a large oesophageal gizzard, the metandric male apparatus and the prostates in 17 fit. There are no calciferous glands in 9, but the oesophagus is slightly lobate between segments $8-10$. A spermathecae in 8 completely lacking, might be it was mistaken for the well developed nephridial bladder. 

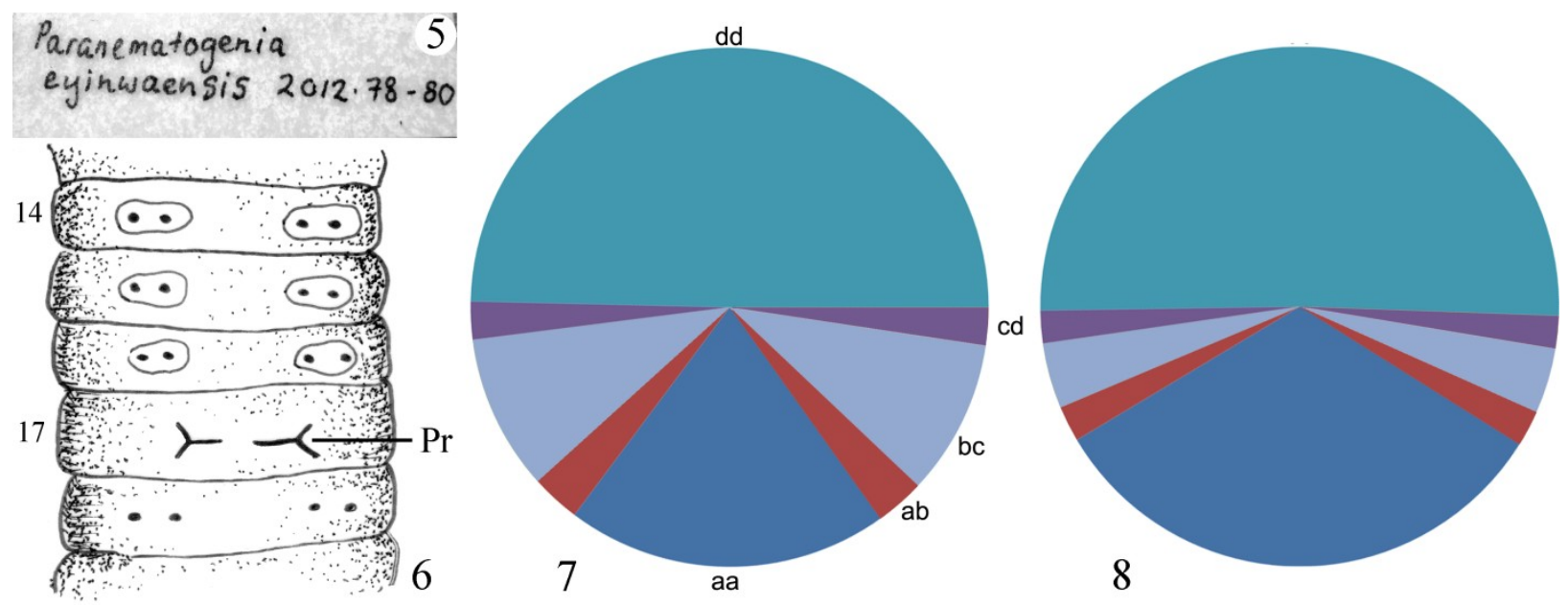

Figures 5-7. Paranematogenia eyinwaensis Aladesida \& Owa, 2015. $5=$ vial label, $6=$ clitellar region from ventral view, $7=$ setal arrangement in segment $14,8=$ setal arrangement in segment $25 . \operatorname{Pr} p=$ prostate pores.

The authors relegated their new genus to Ocnerodrilidae, however the well-developed gizzard, the presence of euprostates with penial setae attached and furthermore the structure of the excretory system place this species to the subfamily Pareudrilinae of the family Eudrilidae. The structure of the hind end of the oesophagus is reminiscent of some West African Stuhlmannia Michaelsen, 1890 species which also show high vascularisation in the region of segment 16 (Sims 1987) however, they have single prostatic pore. The pareudriline genera with paired prostatic pores are Nemertodrilus Michaelsen, 1890 and Pareudrilus Beddard, 1894. Nemertodrilus is holandric and lacks penial setae but interestingly, N. grieus Michaelsen, 1890 possesses long tubelike vesicles in 12 running back to 18 similar as in P. eyinwaensis. Although, Pareudrilus possesses penial setae, it is holandric and has united female and spermathecal pores.

Unfortunately the juvenile stage of the ovospermathecal system prevents the exact identification of the specimens published under the name Paranematogenia eyinwaensis.

Acknowledgements - This research was supported by the grant EFOP-3.6.1-16-2016-00001 ("Complex improvement ofresearch capacities and services at Eszterházy Károly University")

\section{REFERENCES}

AladesidA, A.A. \& OwA, S.O. (2015): Four new earthworm genera (Annelida, Oligochaeta) from Nigeria. Journal of Natural Science, Engineering and Technology, 14(1): 100-109.

Fragoso, C. \& Brown, G.G. (2007): Ecología y taxonomía de las lombrices de tierra en Latinoamérica: El primer Encuentro Latino-Americano de Ecología y Taxonomía de Oligoquetos (ELAE TAO1). In. Brown, G.G. \& FraGoso, G. (Eds.) Minhocas na América Latina: Biodiversidade e Ecologia, EMBRAPA Soja. Londrina, p. 25-68.

ICZN (1999): International Code of Zoological Nomenclature. Fourth Edition. London, U.K. [available online at https:/www.iczn.org/the-code/theinternational-code-of-zoological-nomenclature/thecode-online/] International Trust for Zoological Nomenclature.

NARAYANAN, S.P., SATHRumithra, S., Christopher, G. \& JULKA, J.M. (2017): New species and new records of earthworms of the genus Drawida from Kerala part of the Western Ghats biodiversity hotspot, India (Oligochaeta, Moniligastridae). ZooKeys, 691: 1-18. doi: 10.3897/zookeys.691.13174

SEgun, A.O. (1976-1990): Species names published by A.O. Segun. http://bionames.org/authors/A O Segun [Accessed: 11.05.2020] 
SIMS, R.W. (1987): A review of the Central African earthworm family Eudrilidae (Oligochaeta). In. Bonvicini Pagliai, A.M. \& OMOdeO, P. (Eds.) On earthworms. Selected symposia and monographs, UZI, 2. Mucchi, Modena, p. 359-388.
OwA, S.O. (1990-1998): Species names published by S.O. Owa. http://bionames.org/authors/S O Owa [Accessed: 11.05.2020] 